\title{
Cricket injuries - a longitudinal study of the nature of injuries in South African cricketers
}

\author{
R A Stretch' \\ D J L Venter ${ }^{2}$ \\ 'Sport Bureau, University of Port Elizabeth, South Africa \\ ${ }^{2}$ Department of Mathematical Statistics, University of Port Elizabeth, South Africa
}

\begin{abstract}
Introduction. To determine the incidence and nature of injuries sustained by elite cricketers during a four-season period in order to identify the evidence of any injury patterns associated with these injuries.

Methods. Thirty-eight physiotherapists and 14 doctors working with 11 provincial teams and the South African national team completed a questionnaire for each cricketer who presented with an injury during each season in order to determine: (i) anatomical site of injury, (i) month of injury during the season; (iii) the diagnosis; (iv) mechanism of injury: ( $v$ ) whether it was a recurrence of an injury sustained in a previous season, (vi) whether the injury had recurred again during that season; and (vii) biographical data:

Results. The results showed that 1155 injuries were sustained by 594 cricketers, with an average of two injuries per player. Bowling (41\%), fielding and wicketkeeping $(29 \%)$ and batting $(17 \%)$ accounted for the majority of the injuries. The lower limbs (50\%), upper limbs $(23 \%)$ and back and trunk (23\%) were most commonly injured. The injuries occurred primarily during first-class matches $(29 \%)$, limited-overs matches $(26 \%)$ and practices $(28 \%)$ during the early part of the season. Acute injuries made up $66 \%$ of the injuries. Mainly soft tissue injuries occurred, predominantly muscle $(41 \%)$ joint $(18 \%)$, tendon $(13 \%)$ and ligament $(6 \%)$ injuries. The primary mechanism of injury was the delivery and follow through of the fast bowler $(26 \%$ ), overuse $(19 \%)$, running, diving, catching and throwing the ball when fielding $(22 \%)$ and various batting situations such as
\end{abstract}

\section{CORRESPONDENCE:}

\author{
Richard Stretch \\ Sport Bureau \\ University of Port Elizabeth \\ PO Box 1600 \\ Port Elizabeth \\ 6000 \\ Tel: 041-504 2584 \\ Fax: 041-583 2605 \\ E-mail: sparas@upe.ac.za
}

being struck while batting $(7 \%$, running between the wickets $(5 \%)$ and batting for long periods at a time $(4 \%)$ Conclusion. The results indicate a pattern of cause of injury, with cricketers most likely to sustain acute injuries to the soft tissues of the lower limb as a result of bowling. fielding and overuse.

\section{Introduction}

In 1998 the Research Committee of the United Cricket Board of South Africa (UCBSA) identified the need for a long-term investigation into the nature of injuries sustained by elite cricketers. Although a number of investigations into the incidence and nature of injuries sustained by cricketers had been carried out, the literature reviewed showed that that stage no long-term investigation had been conducted to determine whether any injury patterns could be identified. Thus, this investigation was commenced with the assistance of the medical and physiotherapy staff of the various provincial cricket federations in South Africa. The findings of the first three seasons having been previously published. ${ }^{3-5,7}$ This paper includes the injury data for these three seasons (1998 - $1999\left(\mathrm{~S}_{1}\right), 1999-2000\left(\mathrm{~S}_{2}\right), 2000-2001\left(\mathrm{~S}_{3}\right)$, as well as the $2001-2002$ season $\left(S_{4}\right)$ in order to present an injury profile and to identify any injury patterns.

\section{Methods}

The doctors and physiotherapists working with the South African team and the 11 provincial teams were required to complete a questionnaire for all cricketers who presented with an injury. It was designed to obtain the following information: (i) anatomical site of injury; (ii) month of injury during the season; (iii) the diagnosis; (iv) mechanism of injury; ( $v$ ) whether it was a recurrence of an injury sustained in a previous season; ( $v i)$ whether the injury had recurred again during the season; and (vii) biographical data.

The injuries were grouped according to the anatomical region that was injured, as follows: (i) the head, neck and face; (ii) the upper limbs; (iii) the back and trunk; and (iv) the lower limbs. These injuries were classified according to whether they were sustained during batting, bowling or fielding. The time in the season when the injury occurred was recorded. The off-season was defined as that part of the season when no specific cricket practice or training was per- 
formed. The pre-season, a 2-month period, was that part of the season when specific cricket practice and training were undertaken before the commencement of matches. The season was defined as that part of the season where matches were played and included international tours. For the purpose of this survey the incidence of injury in the various phases was expressed as a percentage of the total number of injuries recorded.

An injury was defined as any pain that occurred which prevented the player from completing that particular match, practice or training session and caused the player to seek medical attention. Acute injuries were those of rapid onset, chronic injuries were those involving prolonged or extended onset, while acute-on-chronic injuries showed the increased symptoms of a chronic injury, but were brought about by movements causing rapid onset. The BMDP Statistical Software Package (BMDP, 1993, Los Angeles, BMDP Statistical Software Inc.) was used to compute descriptive statistics.

\section{Results}

During the period under review the physiotherapists and doctors working with the 11 provincial teams and the national team recorded 1155 injuries sustained by 594 cricketers, with an average of two injuries per player (Table I). The 38 physiotherapists recorded 989 injuries $(86 \%)$, while the 14 doctors recorded 166 injuries (14\%). The demographic data of players are presented in Table II. The younger players (up to 24 years) sustained more overuse $(62 \%)$ and bowling $(54 \%)$ injuries than the older players.

TABLE I. Number of players and injuries during $S_{1}$ $(1998-1999), S_{2}(1999-2000), S_{3}(2000-2001)$ and $S_{4}$ $(2001-2002)$

\begin{tabular}{|cccccc}
\hline & $S_{1}$ & $s_{2}$ & $s_{3}$ & $s_{4}$ & $s_{\text {Total }}$ \\
\hline Players $(M)$ & 88 & 160 & 188 & 158 & 594 \\
njurles $(M)$ & 163 & 258 & 391 & 343 & 155 \\
Mean $(N)$ & 1.9 & 1.6 & 21 & 2.4 & 19 \\
\hline
\end{tabular}

TABLE II. Demographic data of players $(N=594)$ in the study

\begin{tabular}{|c|c|c|c|c|c|}
\hline & $\begin{array}{l}\mathbf{s}_{1} \\
(\%)\end{array}$ & $\begin{array}{c}\mathbf{s}_{2} \\
(\%)\end{array}$ & $\begin{array}{r}S_{3} \\
(\%)\end{array}$ & $\begin{array}{l}S_{4} \\
(\%)\end{array}$ & $S_{\text {Total }}(\%)$ \\
\hline \multicolumn{6}{|l|}{ Age } \\
\hline $12 \cdot 18$ years & 1 & 10 & 5 & 5 & 5 \\
\hline $19-24$ years & 45 & 47 & 49 & 44 & 46 \\
\hline $25-29$ years & 28 & 25 & 23 & 33 & 27 \\
\hline 29 years > & 26 & 18 & 24 & 19 & 22 \\
\hline \multicolumn{6}{|l|}{ Role } \\
\hline All-rounder & 34 & 26 & 31 & 34 & 31 \\
\hline Batsman & 28 & 21 & 25 & 24 & 24 \\
\hline Fast bowler & 27. & 35 & 35 & 31 & 33 \\
\hline Spin bowler & 2 & 11 & 8 & 6 & 7 \\
\hline Wieket keep & 9 & 7 & 2 & 55 & \\
\hline \multicolumn{6}{|c|}{$\mathrm{S}_{1}=1998-1909, \mathrm{~S}_{2}=1999,2000, \mathrm{~S}_{3}=2000-2001 \mathrm{and} \mathrm{S}_{4}=2001-2002$. } \\
\hline
\end{tabular}

The injuries occurred predominantly when practising or playing for provincial (34\%), provincial ' $B$ ' $(31 \%)$ and international $(12 \%)$ teams. Eight per cent of injuries occurred when representing club and school teams respectively. Players attending the various provincial and national cricket academies suffered $7 \%$ of the total injuries.

The injuries occurred equally during first-class (29\%), and limited-overs $(26 \%)$ matches and during practices and training $(28 \%)$. The gradual onset of the injury, caused as a result of a combination of training, practising and playing matches, over a period of time, accounted for $18 \%$ of the injuries.

The chronicity and occurrence of injuries is shown in Fig. 1, with the majority of injuries classified as acute injuries. First-time injuries accounted for $66 \%$ of the injuries, with the younger players (up to 24 years) sustaining $54 \%$ of these injuries (Fig. 2). Of the new or first-time injuries sustained, $40 \%$ and $30 \%$ were respectively bowling and fielding injuries sustained for the first time. Recurrent injuries from the previous season made up $22 \%$ of the injuries, while the players over 24 years of age sustained $59 \%$ of these injuries, with

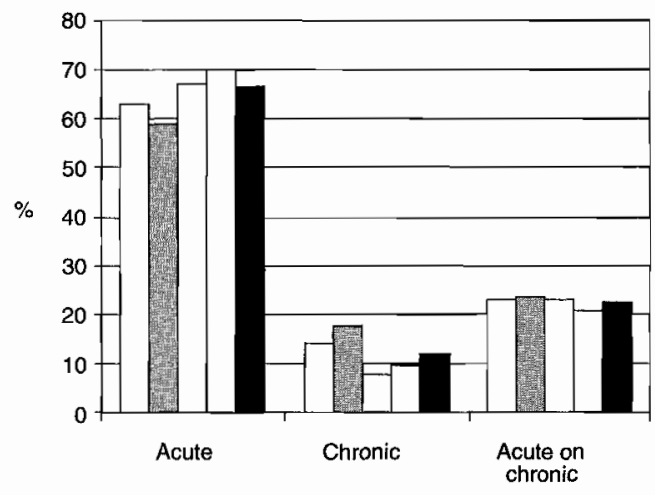

$\square$ Season 1 圈 Season $2 \square$ Season $3 \square$ Season $4 \square$ Total

Fig. 1. Chronicity of injuries. (Season $1=1998-1999$, Season $2=1999-2000$, Season $3=2000-2001$ and Season $4=2001$ - 2002).

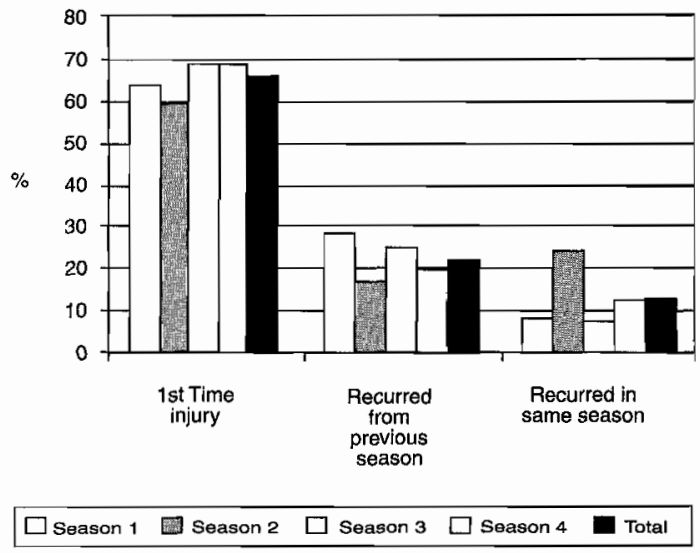

Fig. 2. Occurrence of injuries. (Season $1=1998$ - 1999, Season $2=1999-2000$, Season $3=2000-2001$ and Season $4=2001-2002$ ). 
$43 \%$ of these injuries recurring again as a result of bowling. A similar rate for injuries sustained during the season and recurring again during the same season was found for the players up to 24 years ( $49 \%$ ) and over 24 years $(51 \%)$, with $44 \%$ of these injuries recurring again as a result of bowling. The relationship between both the mechanism of injury (Fig. 3) and the nature of injury (Fig. 4) and the number of injuries sustained for the first time, recurrent injuries from the previous season and those that recurred again during the same season are shown.

The regional distribution of the injuries is presented in Table III. Lower limb injuries accounted for half of the injuries $(50 \%)$, with injuries to the patella femoral joint and knee $(19 \%)$, hamstring $(18 \%)$ and quadriceps $(11 \%)$ muscles, ankle $(12 \%)$ and groin $(8 \%)$, comprising the majority of the 574 lower limb injuries. The hamstring injuries were mainly muscle strains $(N=78)$ and tears $(N=19)$, while injuries to the quadriceps were mainly muscle strains $(N=48)$. The knee and patella femoral joint injuries were mainly muscle strains $(N=40)$ and ligament tears $(N=9)$. These injuries were primarily caused by bowling (hamstring $N=32$, quadriceps $N=26$, patella femoral joint and knee $N=24$ ), fielding (hamstring $N=14$, quadriceps $N=11$, patella femoral joint and knee $N=23$ ) and overuse (hamstring $N=13$, quadriceps $N=6$, patella and knee $N=31$ ).

The 266 upper limb injuries were predominantly to the phalange and metacarpals (33\%), gleno-humeral joint (23\%) and the elbow joint (8\%). Injuries to the phalanges and metacarpals $(N=88)$ were primarily caused by impact from the ball while batting $(N=32)$ and fielding $(N=42)$, mainly

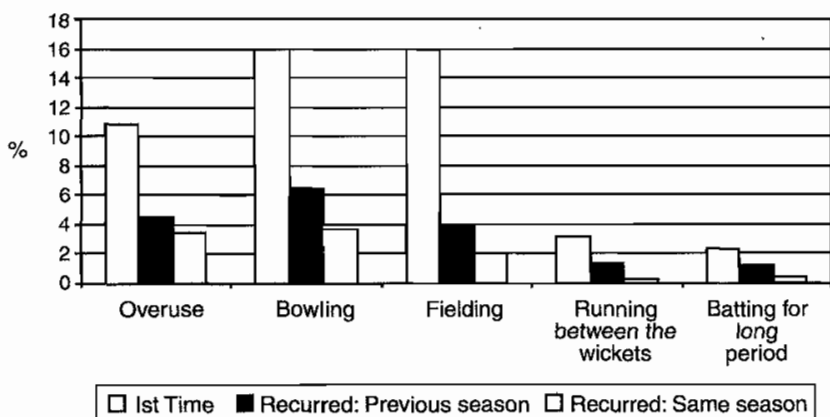

Fig. 3. Relationship between the mechanism and recurrence of injury.

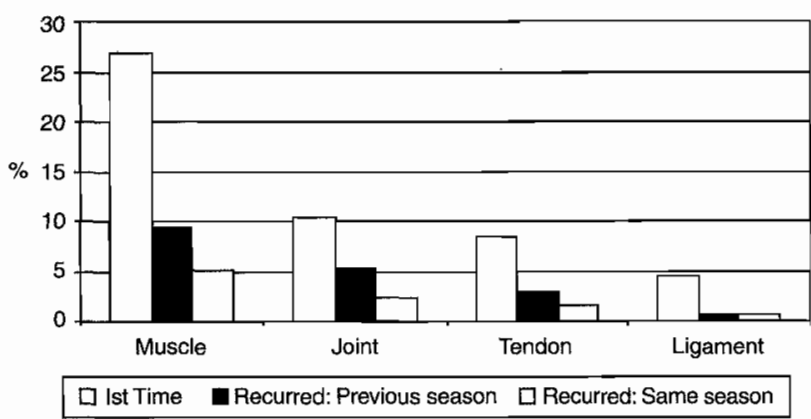

Fig. 4. Relationship between the nature and recurrence of injury.

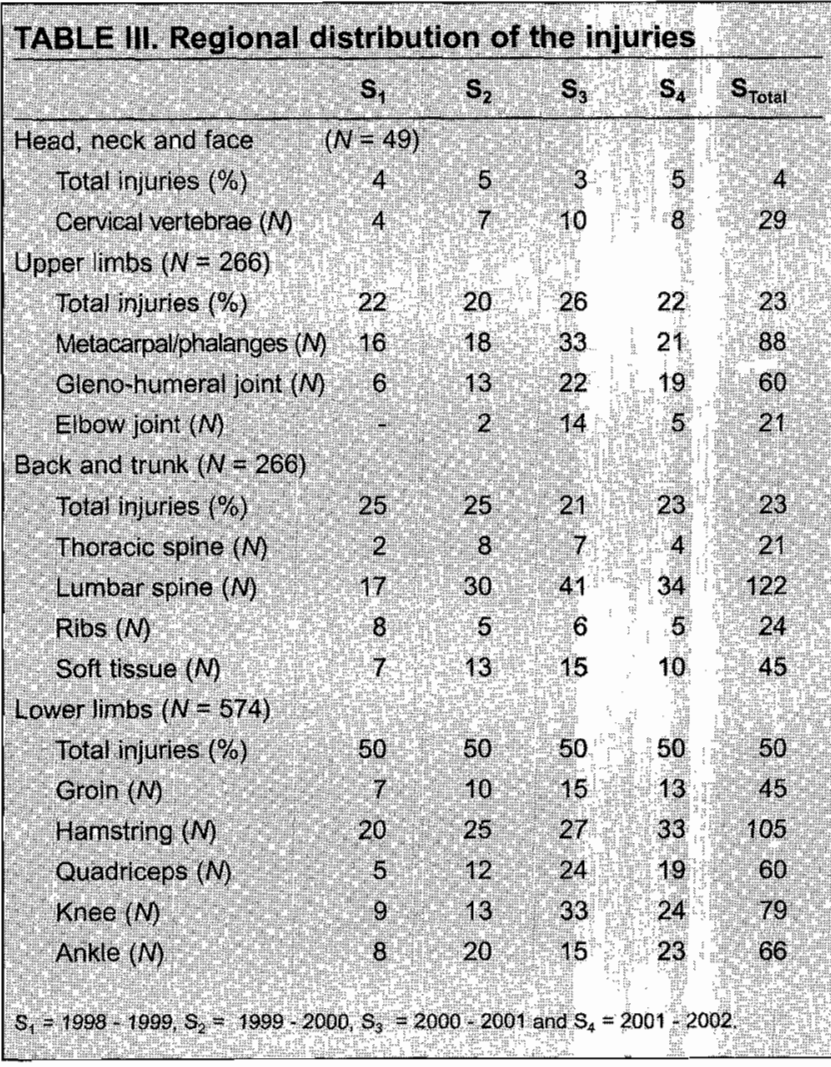

resulting in fractures $(N=30)$ and joint $(N=26)$ injuries. The gleno-humeral injuries $(N=60)$ were predominantly muscle $(N=23)$, tendon $(N=16)$ and joint $(N=13)$ injuries caused by fielding, including throwing $(N=32)$, overuse $(N=12)$ and bowling $(N=6)$. The 21 elbow joint injuries were mainly soft tissue injuries $(N=13)$.

Injuries to the lumbar spine (46\%), abdominal muscles $(17 \%)$, sacro-iliac joint $(9 \%)$ and ribs $(9 \%)$ made up the majority of the 266 back and trunk injuries. The 122 lumbar spine injuries were made up mainly of joint $(N=52)$ and muscle $(N=34)$ injuries and stress fractures $(N=19)$. These injuries were caused by overuse $(N=40)$, bowling $(N=39)$, fielding $(N=14)$ and batting for a long period $(N=11)$.

Of the 49 injuries to the head, neck and face, $29(59 \%)$ were cervical spine injuries, with 15 being muscle spasms or strains. Of these, 9 injuries were as a result of batting for long periods at a time.

Bowling (41\%) and fielding and wicket-keeping (29\%) accounted for the majority of the injuries, with batting accounting for $17 \%$ of the injuries sustained. Of the bowling injuries, $52 \%$ were lower limb injuries and $33 \%$ were back and trunk injuries. Of these, $61 \%$ were acute injuries, $15 \%$ chronic injuries and $24 \%$ acute-on-chronic injuries. The younger players (up to 24 years of age) sustained $54 \%$ of the bowling injuries, with the majority of the stress fractures as a result of bowling. Of the 32 stress fractures, $16 \%$ and $69 \%$ were in players under the age of 18 years and 24 years respectively, with $16 \%$ in players over the age of 35 years.

Batting injuries were primarily lower limb injuries (54\%) and impact injuries to the upper limbs $(22 \%)$, with the players over the age of 24 years sustaining $62 \%$ of these injuries. Of these lower limb injuries, $73 \%$ were acute injuries, $6 \%$ 
chronic injuries and $21 \%$ acute-on-chronic injuries.

The fielding, including wicket-keeping injuries were predominantly to the upper (46\%) and lower $(38 \%)$ limbs, with the players under the age of 24 years sustaining $53 \%$ of these injuries. Of these, $73 \%$ were acute injuries, $9 \%$ chronic injuries and $18 \%$ acute-on-chronic injuries. Fielding accounted for $14(48 \%)$ of the dislocation injuries.

The injuries occurred during the pre-season (10\%) (September), the early part of the season (33\%) (October and November), mid-season (21\%) (December and January), in the latter part of the season (13\%) (February and March) and during the 'off-season' (23\%) (AprilAugust).

The severity of the injuries varied, with $36 \%$ of the injuries preventing the player from completing the training or practice session or the match when the injury occurred. The more severe injuries resulted in $12 \%, 13 \%$ and $12 \%$ of the players not being able to practice or play matches for 1 - 3 days, 4 7 days and $8-20$ days respectively. A further $27 \%$ of the injured players were not able to practice or play matches for more than 21 days.

The primary mechanism of injury was the delivery and follow through of the fast bowler $(26 \%)$, overuse $(19 \%)$, running, diving, catching and throwing the ball when fielding $(22 \%)$ and various batting situations such as being struck while batting $(7 \%)$, running between the wickets $(5 \%)$ and batting for long periods at a time $(4 \%)$.

Mainly soft tissue injuries occurred, made up predominantly of muscle strains $(33 \%)$, tears $(5 \%)$, spasms $(8 \%)$, haematomas $(5 \%)$, tendonitis $(7 \%)$, ligament tears $(2 \%)$ and rotator cuff injuries $(3 \%)$. The primary mechanism of the muscle injuries was bowling (Fig. 5). Other diagnoses included sprains $(5 \%)$, impingements $(3 \%)$ and fractures to the phalanges, metacarpals and carpals (3\%) (Table IV).

\section{Discussion}

The incidence and nature of injuries sustained by cricketers during a four-season period have been presented. The results indicate a pattern of cause and risk of injury, major

\section{TABLE IV Diagnosis of the injuries}

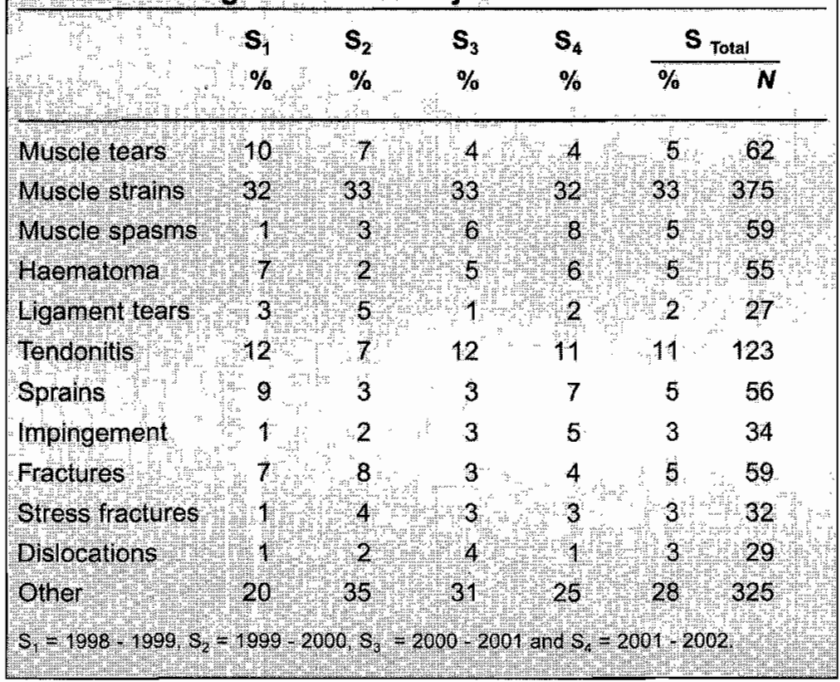

types of injuries being acute soft tissue injuries to the lower limbs as a result of bowling, fielding and overuse, with the younger players most susceptible to injuries. Once the player has sustained the first injury of his career, he is likely to sustain recurring injuries again during the same season or during subsequent seasons, with the older players likely to sustain these recurrent injuries as a result of bowling.

The nature of the modern game requires substantial investment of time if all the aspects of performance enhancement are to be adopted, in particular the technical and physical aspects. The early specialisation of players resulted in the need for training sessions to be more effective and purposeful in order to encourage sound practices and greater optimisation of performance in the game. As a result cricket practices moved from the more traditional 'have a bat, have a bowl and have a chat' to skill and fitness training sessions with more purpose. Clearly, this has had limited effectiveness and may have resulted in the increase in overuse injuries, as well as acute soft tissue injuries being sustained by the younger players.

From the data presented it would appear that there is a low incidence of injury in the $12-18$ year age group. This, however, may be misleading due to the low number of cricketers in this age group playing at this level. A previous study ${ }^{6}$ of schoolboy cricketers showed an overall incidence of injuries of $49 \%$, with bowlers $(47 \%)$ at greater risk of injury than batsmen $(30 \%)$ and fielders $(23 \%)$.

Touch rugby and soccer are sports that most South Africans enjoy, and are commonly used during the warm-up to add variety to the programme. Although not a major concern at present, these sports have over the past four seasons resulted in eight injuries while being used as warm-up prior to practices and matches. Thus, they should be used with great caution and the activity modified so as to reduce the risk of injury.

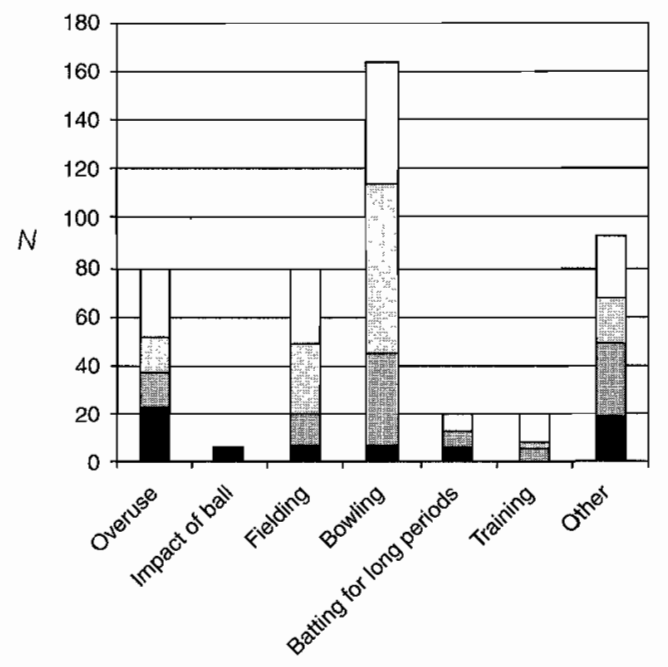

Season 1 Season $2 \quad$ Season $3 \quad \square$ Season 4

Fig. 5. Mechanism of muscle injuries over the 4-season period (Season $1=1998$ - 1999, Season $2=1999-2000$, Season $3=2000-2001$ and Season $4=2001$ - 2002). 
The reduction in the number of stress fractures as a result of over-use and bowling with the incorrect bowling action appears to indicate that the extensive educational process which has involved a large number of primary and high school teachers and coaches has proved successful to a certain extent. These programmes focused on assisting the coaches to identify the correct type of fitness and strength training, the dangers of over-bowling and the correct bowling technique. However, the guidelines set out by the UCBSA with regard to restricting the number of overs bowled per match, week and month needs to be enforced at all levels of the game (Table V).

Coaches, administrators, trainers and parents who are involved with the development and nurturing of the young cricketer need to become aware of the risk factors and to develop the necessary preventative strategies and appropriate steps to ensure that the young player remains injury free for as long as possible. In order to achieve this the potential risk factors of each cricketer should be identified and addressed through a sound training programme that aims to continually assess, analyse, implement and monitor the individual progress of the player. These training sessions need to be directed at specific tasks that are associated with turning potential to performance and not to non-participation through injury.

Similarly, after sustaining an injury the medical personnel and the player need to ensure that a sound rehabilitation programme is followed and the player must not return to match play until he is fully recovered. This is particularly the case when the player has sustained a soft tissue injury.

Further, in support of Orchard et $a l .,{ }^{2}$ it is recommended that researchers collecting injury data agree to a standard definition and method for calculating the incidence of injury. The definition should be simplified to take into account the nature and duration of a cricket match as matches vary from one to five days in length and players are involved in at least two of the three major disciplines of batting, bowling and fielding. This would allow researchers, the medical support staff, and national and international cricket federations to establish a profile of injuries at school, club, provincial (county or state) and international level, enabling them to compare data with other countries and to establish whether international trends are occurring.

\section{Acknowledgements}

The author would like to acknowledge the major contribution made by the doctors and physiotherapists in the data collection for this study.

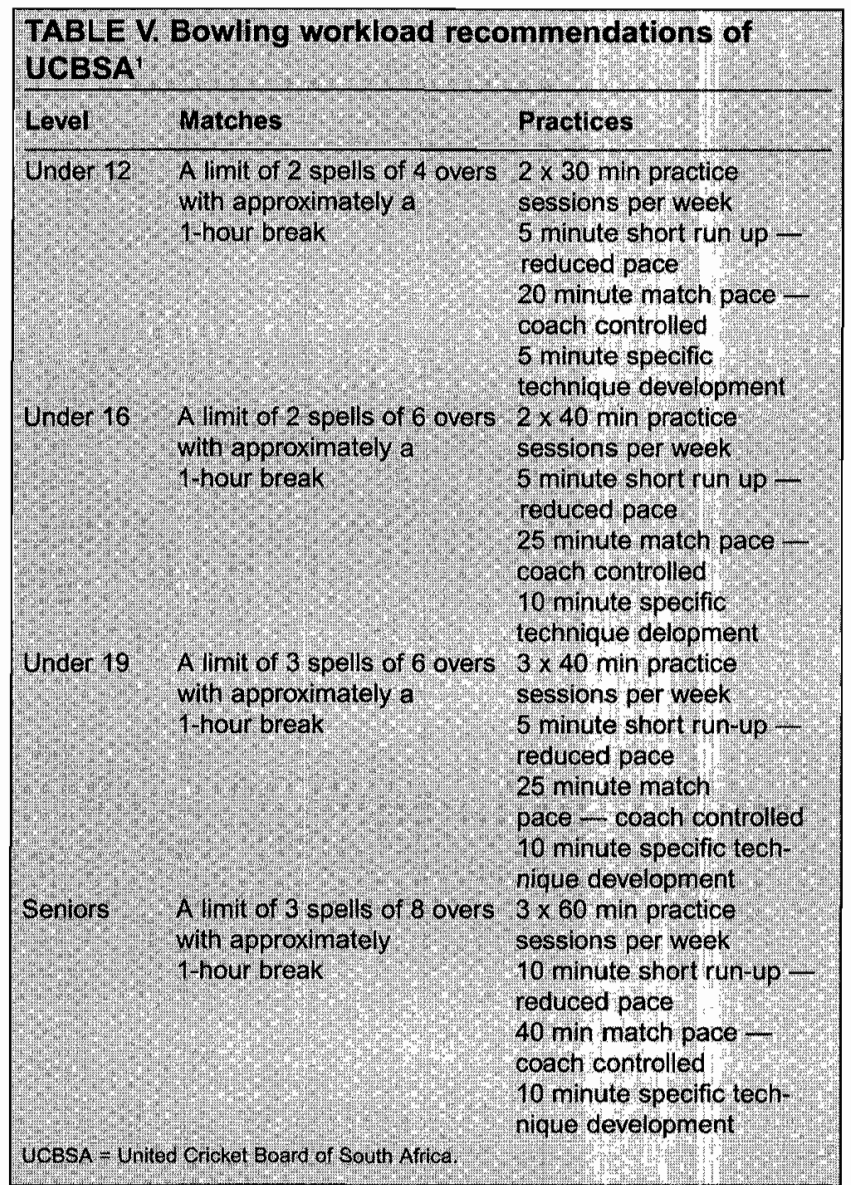

\section{REFERENCES}

1. Elliot $B$, John $D$, Foster D. Factors that predispose a fast bowler to injury. In: Elliot B, Foster D, Blanksby B, eds. Send The Stumps Flying - The Science of Fast Bowling. Nedlands: University of Western Australia Press, 1989: 54-9.

2. Orchard J, James T, Alcott E, Carter S, Farhart P. Injuries in Australian cricket at first class level 1995/1996 to 2000/2001. Br J Sports Med 2002; 36: $270-5$.

3. Stretch RA. Incidence and nature of epidemiological injuries to elite South African cricket players. S Afr Med J 2001; 91: 336-9.

4. Stretch RA. Epidemiology of cricket injuries. Int Sports Med J 2001; 2 (2): 1-7. www.esportmed.com/ismj (last accessed 15 November 2002).

5. Stretch RA. The incidence and nature of epidemiological injuries to elite South African cricket players over a two-season period. South African Journal of Sports Medicine 2001; 8: 17 - 20.

6. Stretch RA. The seasonal incidence and nature of injuries in schoolboy cricketers. S Afr Med J 1995; 85: 1182-4.

7. Stretch RA. Cricket injuries: A longitudinal study of the nature of injuries to South African cricketers. $B r J$ Sports Med (in press). 